\title{
Microvascular Invasion in Small-sized Hepatocellular Carcinoma: Significance for Outcomes Following Hepatectomy and Radiofrequency Ablation
}

\author{
KATSUNORI IMAI, YO-ICHI YAMASHITA, TOSHIHIKO YUSA, YOSUKE NAKAO, RUMI ITOYAMA, \\ SHIGEKI NAKAGAWA, HIROHISA OKABE, AKIRA CHIKAMOTO, TAKATOSHI ISHIKO and HIDEO BABA \\ Department of Gastroenterological Surgery, Graduate School of Life Sciences, \\ Kumamoto University, Kumamoto, Japan
}

\begin{abstract}
Background/Aim: The significance of microvascular invasion (MVI) of hepatocellular carcinoma (HCC) after radiofrequency ablation (RFA) is unknown. Patients and Methods: We studied 149 patients with solitary small-sized $H C C(\leq 3 \mathrm{~cm})$ who underwent hepatectomy, and developed a predictive model of MVI using independent factors related to the presence of MVI. The predictive model was applied to 159 patients who underwent RFA, and their outcomes were examined. Results: A multivariate analysis revealed that $\alpha$ fetoprotein $\geq 15 \mathrm{ng} / \mathrm{ml}$ (relative risk (RR) 3.05, $p=0.02$ ), des- $\gamma$ carboxy prothrombin $\geq 100 \mathrm{mAU} / \mathrm{ml}(R R 4.19, p=0.003)$, and tumor size $\geq 2 \mathrm{~cm}$ ( $R R$ 3.37, $p=0.03$ ) were independent risk factors of MVI. Among the patients who underwent RFA, the survival in patients with risk factors 2-3 was significantly worse, and local recurrence was more frequently obserbed than those with 0-1. Conclusion: When an HCC tumor is expected to display MVI, RFA may not be suitable in terms of poorer survival and local disease-control rates.
\end{abstract}

Hepatocellular carcinoma (HCC) is the sixth most common malignancy worldwide $(1,2)$. Although advances in imaging modalities, surgical techniques, and surveillance programs have improved the outcomes of patients with HCC, the longterm outcomes of $\mathrm{HCC}$ patients remain unsatisfactory because of the high frequency of recurrence (3).

Microvascular invasion (MVI) is a histological feature that indicates aggressive behavior of HCC. The presence of MVI

Correspondence to: Katsunori Imai, Department of Gastroenterological Surgery, Graduate School of Life Sciences, Kumamoto University, 1-1-1 Honjo, Chuo-ku, Kumamoto 8608556, Japan. Tel: +81 963735212, Fax: +81 963714378, e-mail: katsuimai@hotmail.com

Key Words: Hepatocellular carcinoma, radiofrequency ablation, microvascular invasion, predictive model, local recurrence. has been reported to be a poor-prognosis factor of recurrence and long-term survival after liver resection or transplantation (4-14). Macrovascular invasion can often be detected before surgery by imaging modalities including ultrasonography (US), enhanced computed tomography (CT), and magnetic resonance (MR) imaging. However, the detection of MVI by preoperative imaging modalities is difficult, and preoperative prediction of MVI is thus an issue of great importance for planning the treatment of HCC. As a consequence, considerable efforts have been made to predict MVI before surgery (14-24).

Radiofrequency ablation (RFA) is a well-established local treatment designed to produce localized tumor destruction by heating the tumor tissue and the surrounding liver tissue. Because of its excellent efficacy, repeatability, safety, and low invasiveness, RFA is gradually becoming an alternative procedure for small-sized HCC. However, the significance of MVI in patients who underwent RFA is unclear, because the diagnosis of MVI is based on histological examination of surgical specimens.

The current study aimed to develop a simple predictive model of MVI in resected small-sized $\mathrm{HCC}$, and to investigate the prognostic significance of MVI expectation in patients who underwent RFA based on the proposed predictive model.

\section{Patients and Methods}

Patients who underwent surgical treatment with curative intent for HCC between 2000 and 2015 at the Kumamoto University Hospital, Kumamoto, Japan were identified retrospectively from a prospectively maintained database. Among them, patients with solitary small-sized HCC $(\leq 3 \mathrm{~cm})$ who underwent either hepatectomy or RFA were identified and enrolled in this study. Patients who presented with HCC tumors with MVI on the preoperative imaging modalities were excluded from this study. Based on an analysis of clinicopathological variables in patients who underwent hepatectomy, a predictive model of MVI was 
developed. Subsequently, this predictive model was applied to the cohort of patients who underwent RFA and the significance of MVI expectation for long-term outcome after RFA was examined.

Preoperative workups. The diagnosis of HCC was based on routine imaging modalities including US, dynamic CT, MR imaging, and CT angiography. Because of the specific complication of cancer cell seeding, liver biopsy prior to RFA was not suggested in our department, as described previously (25). Therefore, making a diagnosis of HCC without pathological evidence mainly depended on typical findings, i.e., early-phase enhancement and late-phase contrast washout in at least two imaging techniques. Elevation of tumor markers including $\alpha$-fetoprotein (AFP), Lens culinaris agglutinin-reactive fraction of AFP (AFP-L3), and des- $\gamma$-carboxy prothrombin (DCP), as well as the background of hepatitis virus infection, were also considered supplemental, as described previously $(25,26)$.

Before treatment, all patients underwent routine laboratory tests, including measurement of tumor markers such as AFP, AFP-L3, and DCP, liver function tests including indocyanine retention rate at 15 min (ICG-R15), and 99mTc-galactosyl human serum albumin (GSA) scintigraphy. The surgical procedure was selected based on the tumor location, extent of the tumor, liver functional reserve, and the patient's general condition, as described previously $(25,26)$. Briefly, hepatectomy was considered as the treatment of first choice for patients with good liver functional reserve, and anatomical resection was employed if the liver function allowed. RFA was selected for patients with a deeply located tumor requiring major hepatectomy leading to insufficient remnant liver volume, insufficient liver functional reserve, or high operative risk associated with their general condition $(25,26)$. This study was approved by the Institutional Ethics Committee of Kumamoto University Hospital and was performed in accordance with the 1975 Declaration of Helsinki. Written informed consent was obtained from all patients before treatment.

Surgical strategy. The type of hepatectomy was selected based on tumor location, extent of tumor invasion, parenchymal liver function, and the patient's general condition, as described previously (25-27). If the liver function allowed, anatomical resection was employed. In patients with insufficient liver functional reserve, limited resection was performed.

RFA was performed using a cooled-tip electrode with a length of 2-3 cm (Radionics, Burlington, MA, USA) and connected to a 500$\mathrm{kHz}$ RF generator (Radionics, Burlington, MA, USA) under the programmed cyclic impedance control condition as described previously $(25,26)$. A $17-\mathrm{G}$ electrode was inserted into the lesion under either US guidance or direct visual guidance, ablation was initiated, and the power was increased to $60 \mathrm{~W}$ in a 2-cm length needle and $80 \mathrm{~W}$ in a $3-\mathrm{cm}$ length needle. The duration of maximum ablation was $8-10 \mathrm{~min}$ and the impedance was closely monitored. All ablations aimed to achieve at least a $0.5-\mathrm{cm}$ margin of nontumorous liver parenchyma, if possible, in a single session.

Postoperative workups. All postoperative complications were graded according to the Dindo-Clavien classification (28). After treatment, all patients underwent regular follow-up to monitor serum AFP, AFP-L3 and DCP levels, and imaging studies, including US and dynamic CT every 2-4 months to detect any intrahepatic or distant recurrence. Recurrence was defined as the appearance of a lesion with radiological features typical of HCC, as confirmed by US, CT, or MR imaging. Local recurrence was defined as the reappearance of tumor progression either within the ablation site or in contact with the ablation site on contrast-enhanced CT or MR imaging $(26,29)$. When tumor recurrence was confined to the remnant liver, various treatment modalities were selected, including repeat hepatectomy, RFA, transcatheter arterial chemoembolization, chemotherapy with sorafenib, or a combination of these methods.

Histological study. All resected specimens were fixed in $10 \%$ formaldehyde solution and cut into $0.5-1.0-\mathrm{cm}$ slices. After macroscopic examination, the slices were embedded in paraffin, and 5 -mm sections were stained with hematoxylin-eosin. A histological examination of the resected specimens was performed by pathologists who did not know the outcome of the patients. Histological grading of tumor differentiation was made on the highest-grade areas of each patient. MVI was defined as a tumor cell within a vascular space lined by endothelium that was visible only on microscopy.

Statistical analysis. Continuous variables are expressed as median (range). Continuous and categorical variables were compared using the Mann-Whitney $U$-test and the $\chi^{2}$ test, respectively. Survival analyses were performed using the Kaplan-Meier method, and the results were compared using the log-rank test. Overall survival (OS) was calculated from the date of treatment until death or the last follow-up examination. Disease-free survival (DFS) was defined as the period between treatment and the first postoperative recurrence or death. For the univariate analysis of the factors that predicted MVI, the optimal cut-off values of continuous variables for differentiation between the groups were determined based on receiver operating characteristics (ROC) analysis. Variables with a $p$-value of $\leq 0.10$ in the univariate analysis were subjected to a multivariate logistic regression analysis using a stepwise backward elimination procedure. A predictive model was then developed based on the results of the multivariate logistic analysis, as described previously $(30,31)$. All statistical analyses were performed using the JMP (SAS Institute, Cary, North Carolina, USA) and R version 3.1.1 (http://www.r-project.org) software programs. $p$-Values of $<0.05$ were considered to indicate statistical significance.

\section{Results}

Between 2000 and 2015, a total of 308 patients underwent either hepatectomy $(n=149)$ or RFA $(n=159)$ for solitary smallsized $\mathrm{HCC}(\leq 3 \mathrm{~cm})$ as an initial treatment at our institution. The background characteristics of these two cohorts are summarized in Table I. Compared to the hepatectomy group, the patients in the RFA group were characterized primarily by increased serum concentration of total bilirubin; decreased serum concentration of albumin, platelet count, and prothrombin activity; and impaired ICG-R15 and uptake ratio of the liver to the liver plus heart at $15 \mathrm{~min}$ (LHL15) as determined by ${ }^{99 \mathrm{~m}} \mathrm{Tc}-\mathrm{GSA}$ scintigraphy. These findings suggested that liver function was impaired in the RFA group. On the contrary, the patients in the hepatectomy group had larger tumor size and higher levels of tumor markers, suggesting that their tumors were more advanced. 
In the hepatectomy group, anatomical resection was performed in 64 patients $(43 \%)$. In the RFA group, approaches for ablation were as follows: percutaneous, 88 patients; laparoscopy, 45; thoracoscopy, 21; and laparotomy, five. The operating time was significantly shorter, and the amount of blood loss was smaller in the RFA group than in the hepatectomy group. Complication (Clavien-Dindo $\geq \mathrm{II}$ ) was observed more frequently in the hepatectomy group than in the RFA group.

Median follow-up was 55.6 months after hepatectomy and 45.1 months after RFA. The OS rates at 1,3 , and 5 years were $96.5,91.0$, and $86.7 \%$, and the DFS rates at these times were 86.7, 59.0, and $48.4 \%$ after hepatectomy, respectively (Figure 1a). After RFA, in contrast, the OS rates at 1,3, and 5 years were $99.3,90.7$, and $73.3 \%$, and the DFS rates at these times were $61.0,25.8$, and $11.3 \%$, respectively (Figure 1b).

Predictive factors and predictive model of MVI in resected cases. In the hepatectomy cohort, MVI was observed in 27 of 149 patients (18.1\%, Table I). The OS and DFS in patients who underwent hepatectomy were comparable between patients with and without MVI ( $p=0.21$ and $p=0.09$, respectively, Figure 2), suggesting that MVI did not affect the long-term outcome in patients with solitary small-sized HCC if hepatectomy was performed.

Univariate and multivariate analyses of factors related to MVI are shown in Table II. A univariate analysis revealed that age $<70(p=0.042)$, AFP $\geq 15 \mathrm{ng} / \mathrm{ml}(p=0.007)$, AFP-L3 $\geq 10 \% \quad(p=0.034)$, DCP $\geq 100 \mathrm{mAU} / \mathrm{ml} \quad(p<0.0001)$, and tumor size $\geq 2 \mathrm{~cm}(p=0.0054)$ were significantly associated with MVI. A multivariate analysis revealed that AFP $\geq 15$ $\mathrm{ng} / \mathrm{ml}$ (relative risk (RR) 3.05, $p=0.02$ ), DCP $\geq 100 \mathrm{mAU} / \mathrm{ml}$ (RR 4.19, $p=0.003$ ), and tumor size $\geq 2 \mathrm{~cm}$ (RR 3.37, $p=0.03$ ) were independent predictive factors of MVI.

Subsequently, a predictive model for estimating the probability of MVI was developed using the three independent predictive factors shown in Table III. For patients without any factors, the probability of MVI was 3.3\%. The addition of subsequent factors increased the probability of MVI to $12.5 \%$ for 1 factor, $32.6 \%$ for 2 factors, and $59.6 \%$ for 3 factors. The c-index, a measure of model discrimination represented by the area under the ROC curve, was 0.782 .

Significance of risk3 factors for MVI on outcomes after hepatectomy and RFA. The OS according to the number of risk factors for MVI (0-1 vs. 2-3) was similar after hepatectomy (5-year OS; 0-1: 89.3\%, 2-3: 81.3\%, $p=0.50$, Figure $3 \mathrm{a})$. Likewise, the DFS was also comparable between the groups with the number of risk factors $0-1$ and 2-3 (5-year DFS; 0-1: 47.1\%, 2-3: 51.5\%, $p=0.89$, Figure 3b). In contrast, among the patients who underwent RFA, the OS in patients with risk factors 2-3 was significantly worse than in those with
Table I. Background characteristics of the two cohorts.

\begin{tabular}{|c|c|c|c|}
\hline & $\begin{array}{l}\text { Hepatectomy } \\
\quad(\mathrm{n}=149)\end{array}$ & $\begin{array}{c}\text { RFA } \\
(n=159)\end{array}$ & $p$-Value \\
\hline Age & $68(34-88)$ & $68(43-88)$ & 0.64 \\
\hline Gender (Male/Female) & $107 / 42$ & $96 / 63$ & 0.039 \\
\hline HBs-Ag-positive & $41(27.5 \%)$ & $16(10.1 \%)$ & $<0.0001$ \\
\hline HCV-Ab-positive & $79(53.0 \%)$ & $120(75.5 \%)$ & $<0.0001$ \\
\hline Total bilirubin $(\mathrm{mg} / \mathrm{dl})^{\dagger}$ & $0.8(0.2-2.1)$ & $0.9(0.1-2.5)$ & 0.0004 \\
\hline Albumin $(\mathrm{g} / \mathrm{dl})^{\dagger}$ & $4.1(3.0-5.1)$ & $3.6(2.2-4.8)$ & $<0.0001$ \\
\hline Prothrombin activity $(\%)^{\dagger}$ & $96(43-140)$ & $83(14-125)$ & $<0.0001$ \\
\hline Platelet count $(\times 104)^{\dagger}$ & $13.7(2.9-46.8)$ & $9.2(2.9-3.09)$ & $<0.0001$ \\
\hline ICG-R15 $(\%)^{\dagger}$ & $12.7(1.1-65.4)$ & $27.7(6.6-70.9)$ & $<0.0001$ \\
\hline 99mTc-GSA LHL15 ${ }^{\dagger}$ & $0.89(0.72-0.99)$ & $0.85(0.63-0.95)$ & $<0.0001$ \\
\hline Child-Pugh classification & & & $<0.0001$ \\
\hline 5 & 118 & 65 & \\
\hline 6 & 26 & 38 & \\
\hline 7 & 4 & 44 & \\
\hline 8 & 1 & 11 & \\
\hline 9 & 0 & 0 & \\
\hline 10 & 0 & 1 & \\
\hline Tumor size $(\mathrm{cm})^{\dagger}$ & $2.2(0.8-3.0)$ & $1.9(0.5-3.0)$ & 0.0051 \\
\hline $\operatorname{AFP}(\mathrm{ng} / \mathrm{ml})^{\dagger}$ & $8.2(1.0-4588)$ & $16.5(1.5-864)$ & 0.0058 \\
\hline AFP-L3 >10\% & $26(18.3 \%)$ & $13(8.3 \%)$ & 0.0097 \\
\hline $\mathrm{DCP}(\mathrm{mAU} / \mathrm{ml})^{\dagger}$ & $30(3.6-17505)$ & $25(3.0-1142)$ & 0.025 \\
\hline Anatomical resection & $64(43.0 \%)$ & & \\
\hline \multicolumn{4}{|l|}{ Approach for RFA ablation } \\
\hline Percutaneous & & 88 & \\
\hline Laparoscopy & & 45 & \\
\hline Thoracoscopy & & 21 & \\
\hline Laparotomy & & 5 & \\
\hline Operating time $(\mathrm{min})^{\dagger}$ & $335(144-745)$ & $120(10-375)$ & $<0.0001$ \\
\hline Blood loss $(\mathrm{g})^{\dagger}$ & $300(0-3200)$ & $5(0-609)$ & $<0.0001$ \\
\hline \multicolumn{4}{|l|}{ Complication } \\
\hline (Clavien-Dindo $\geq \mathrm{II}$ ) & $27(18.1 \%)$ & $5(3.1 \%)$ & $<0.0001$ \\
\hline Red blood cell transfusion & $4(2.3 \%)$ & $0(0 \%)$ & 0.015 \\
\hline Microvascular invasion & $27(18.1 \%)$ & & \\
\hline
\end{tabular}

$\dagger^{\dagger}$ Median. RFA: Radiofrequency ablation; HBs-Ag: hepatitis B surface antigen; HCV-Ab: anti-hepatitis $\mathrm{C}$ antibody; ICG-R15: indocyanine green retention rate at $15 \mathrm{~min}$; ${ }^{99 \mathrm{mTc}-G S A}$ : $99 \mathrm{mTc}$-galactosyl human serum albumin; AFP: $\alpha$-fetoprotein; AFP-L3: Lens culinaris agglutininreactive fraction of AFP; DCP: des- $\gamma$-carboxy prothrombin.

0-1 (5-year OS; 0-1: 80.0\%, 2-3: 55.8\%, $p=0.0037$, Figure $3 \mathrm{c})$, although the DFS did not show a significant difference (5-year DFS; 0-1: 11.6\%, 2-3: 6.8\%, $p=0.20$, Figure 3d). Local recurrence after RFA was more frequent in patients with risk factors 2-3 than in those with 0-1 (3-year local recurrence rate; $0-1: 8.4 \%, 2-3: 30.7 \%, p=0.012$, Figure 4$)$.

\section{Discussion}

In the present study, we proposed a predictive model of MVI based on three independent predictive factors identified from a multivariate analysis in patients with solitary small-sized $(\leq 3 \mathrm{~cm}) \mathrm{HCC}$ after hepatectomy. The presence of MVI and 
a

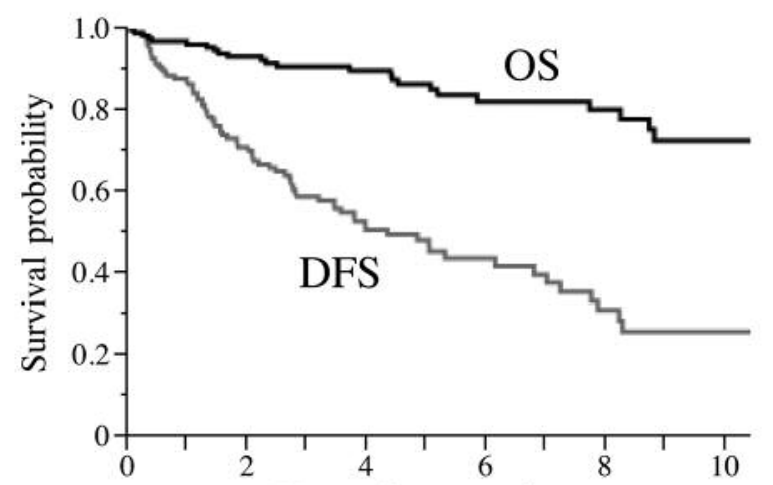

No. at risk

$\begin{array}{rrrrrrr}\text { OS } & 149 & 118 & 92 & 52 & 37 & 18 \\ \text { DFS } & 149 & 88 & 49 & 24 & 14 & 7\end{array}$

b

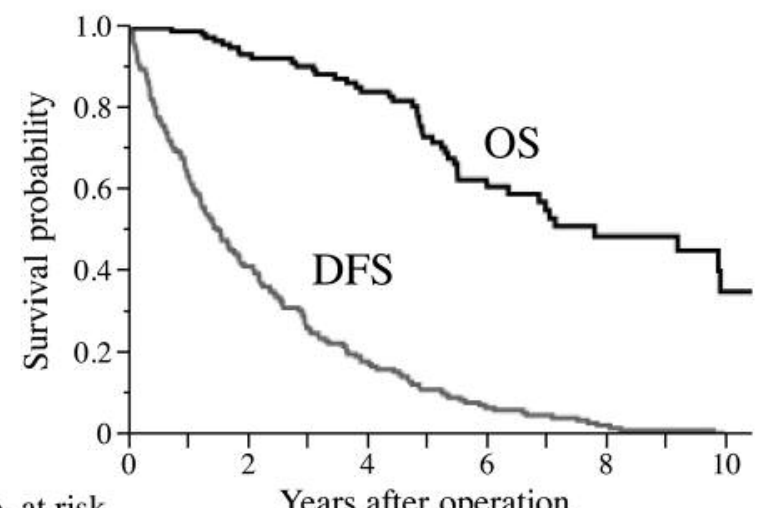

No. at risk

$\begin{array}{rrrrrrr}\text { OS } & 159 & 106 & 77 & 38 & 19 & 8 \\ \text { DFS } & 159 & 67 & 29 & 12 & 5 & -\end{array}$

Figure 1. Overall survival (OS) and disease-free survival (DFS) in patients who underwent hepatectomy (a) and radiofrequency ablation (b).

a

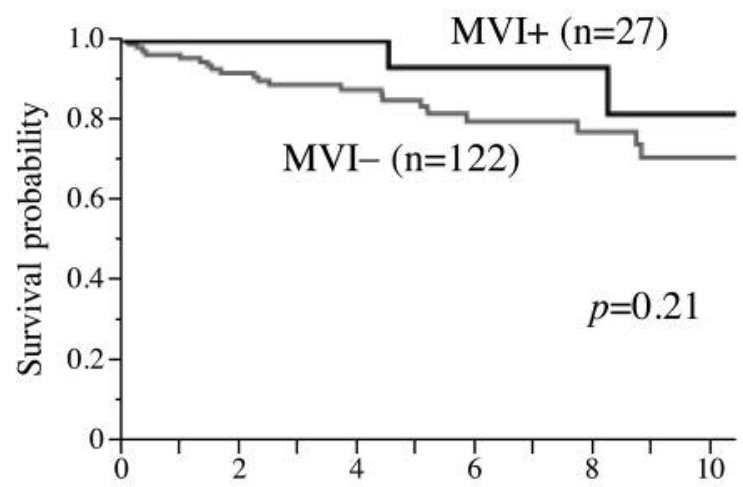

No. at risk

Years after operation

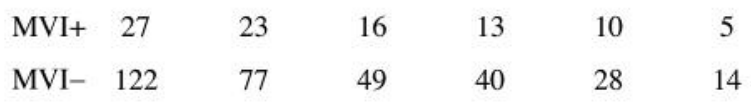

b

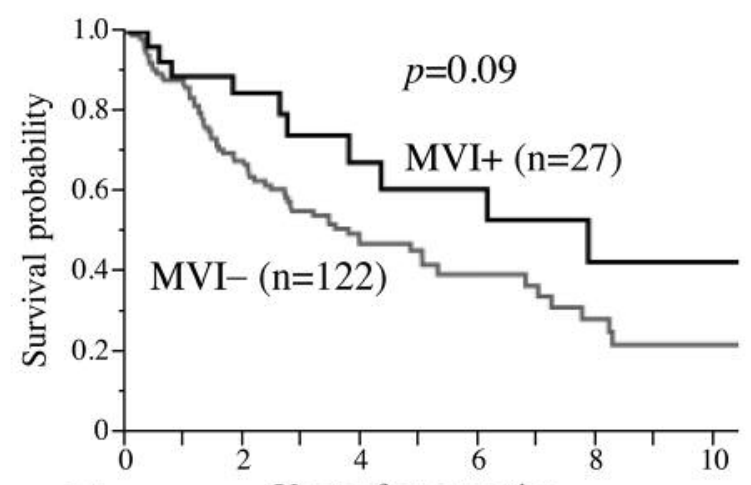

No. at risk

Years after operation

$\begin{array}{ccccccc}\text { MVI+ } & 27 & 20 & 11 & 9 & 5 & 3 \\ \text { MVI- } & 122 & 69 & 39 & 16 & 10 & 5\end{array}$

Figure 2. Overall survival (a) and disease-free survival (b) in patients who underwent hepatectomy according to the presence or absence of microvascular invasion (MVI).

the number of risk factor for MVI did not affect the OS or DFS after hepatectomy for such tumors. However, the patients with MVI-expected HCC (the number of risk factor 2-3) had a worse OS than those with MVI-unexpected HCC (the number of risk factor 0-1) after RFA. Furthermore, local recurrence after RFA was more frequent in patients with MVI-expected HCC (the number of risk factor 2-3).
It is known that MVI is the beginning of intrahepatic dissemination and metastasis of tumor cells in HCC (32). Many previous studies reported that MVI was significantly associated with poor survival after hepatectomy and liver transplantation for HCC (4-14). However, some authors reported that MVI was not a prognostic factor for all HCC patients (33-35). Particularly in those with small-sized HCC 
a
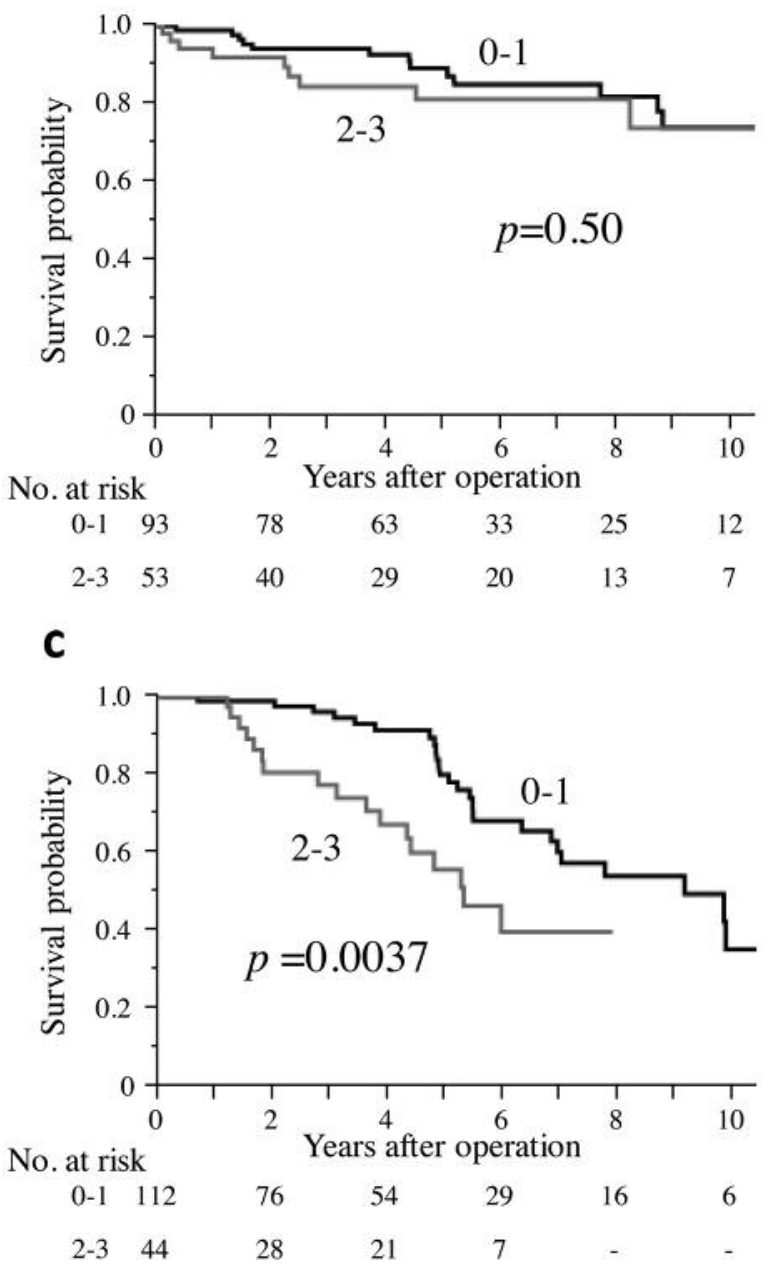

b

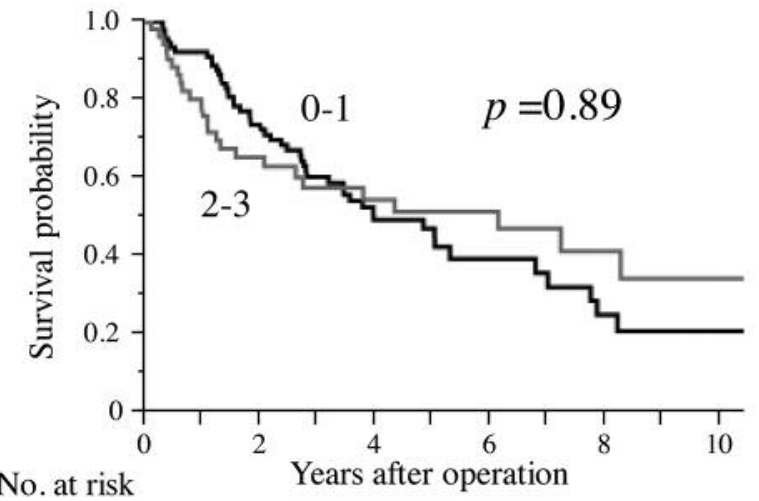

No. at risk

$\begin{array}{lllllll}0-1 & 93 & 59 & 31 & 12 & 7 & 5 \\ 2-3 & 53 & 28 & 19 & 13 & 8 & 3\end{array}$

d

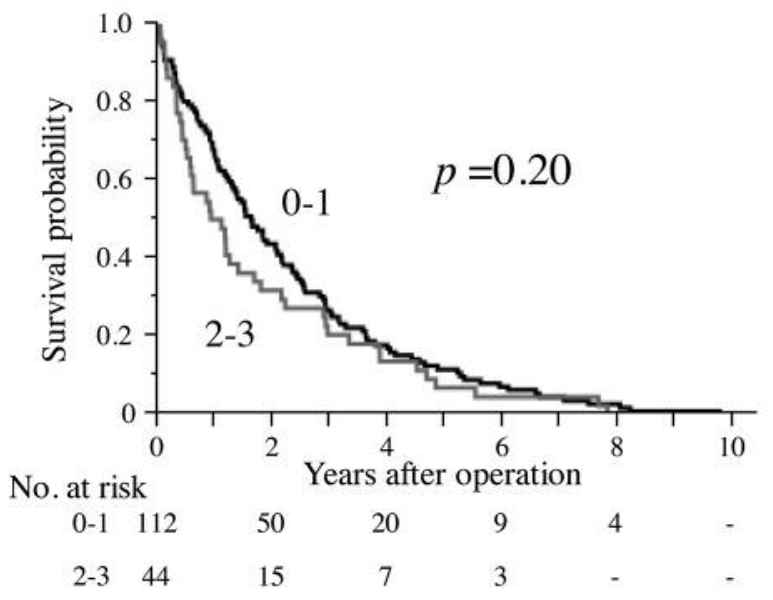

Figure 3. Overall survival (a) and disease-free survival $(b)$ in patients who underwent hepatectomy according to the number of risk factors for microvascular invasion (0-1 vs. 2-3). Overall survival (c) and disease-free survival (d) in patients who underwent radiofrequency ablation according to the number of risk factors for microvascular invasion (0-1 vs. 2-3).

$\leq 2 \mathrm{~cm}$, MVI had a limited clinical value for prognosis. In the present study, The OS and DFS were comparable between patients with and without MVI after hepatectomy (Figure 2). Because the present study included only those patients with a solitary small-sized HCC, the HCC tumors were presumed to be less invasive than large or multiple tumors. In addition, anatomical resection was performed in approximately half of the patients. Although the effect of anatomical resection on tumor recurrence was unclear because of the limited number of patients, these findings suggest that micrometastasisinfiltrating peritumoral vasculatures, so-called MVI, might be removed together with the tumor by hepatectomy in patients with solitary small-sized HCC $\leq 3 \mathrm{~cm}$.

Numerous researchers have attempted to identify possible predictive factors of MVI. Such factors include age (6), tumor size $(10,13,14,18,20)$, multiple nodules (18), gross type (10, 24), tumor markers such as AFP $(13,18)$, AFP-L3 (22) and DCP $(19,20,22,24)$, typical dynamic pattern in enhanced CT (18), maximum standardized uptake value (SUVmax) in positron emission tomography (20), and apparent diffusion coefficient (ADC) value in MR imaging (23). In the present study, we identified three predictors of MVI: AFP $\geq 15(\mathrm{ng} / \mathrm{ml})$, DCP $\geq 100(\mathrm{mAU} / \mathrm{ml})$, and tumor size $\geq 2(\mathrm{~cm})$ (Table III). Based on these predictive factors, a predictive model for MVI was created. According to this model, the presence of these three factors was associated with an increasing probability of MVI up to $59.6 \%$ (Table III), thus confirming their clinical utility for patient selection on a daily practice.

Because the diagnosis of MVI is determined based on histological examination of surgical specimens after 
Table II. Univariate and multivariate analyses of factors for predicting microvascular invasion.

\begin{tabular}{|c|c|c|c|c|c|c|}
\hline & \multirow[b]{2}{*}{ MVI-positive } & \multirow[b]{2}{*}{ MVI-negative } & \multirow{2}{*}{$\begin{array}{c}\text { Univariate } \\
p \text {-Value }\end{array}$} & \multicolumn{3}{|c|}{ Multivariate } \\
\hline & & & & $\mathrm{RR}$ & $95 \% \mathrm{CI}$ & $p$-Value \\
\hline Age $<70$ & $21(77.8 \%)$ & $70(57.4 \%)$ & 0.042 & NS & & \\
\hline Gender (Male) & $18(66.7 \%)$ & $89(73.0 \%)$ & 0.52 & & & \\
\hline HBs-Ag-positive & $10(37.0 \%)$ & $31(25.4 \%)$ & 0.23 & & & \\
\hline HCV-Ab-positive & $13(48.2 \%)$ & $66(54.1 \%)$ & 0.58 & & & \\
\hline Total bilirubin $>1(\mathrm{mg} / \mathrm{dl})$ & $4(14.8 \%)$ & $25(20.5 \%)$ & 0.49 & & & \\
\hline Albumin $>3.5(\mathrm{~g} / \mathrm{dl})$ & $26(96.3 \%)$ & $112(91.8 \%)$ & 0.38 & & & \\
\hline Prothrombin activity $>75(\%)$ & $24(88.9 \%)$ & $114(93.4 \%)$ & 0.44 & & & \\
\hline Platelet count $>15\left(\times 10^{4}\right)$ & $10(37.0 \%)$ & $57(46.7 \%)$ & 0.36 & & & \\
\hline ICG-R15 >10 (\%) & $18(66.7 \%)$ & $80(69.0 \%)$ & 0.82 & & & \\
\hline 99mTc-GSA LHL $15<0.92$ & $16(59.3 \%)$ & $56(47.5 \%)$ & 0.27 & & & \\
\hline $\mathrm{AFP} \geq 15(\mathrm{ng} / \mathrm{ml})$ & $15(55.6 \%)$ & $34(27.9 \%)$ & 0.007 & 3.05 & $1.20-7.99$ & 0.02 \\
\hline AFP-L3 $\geq 10 \%$ & $9(33.3 \%)$ & $17(14.8 \%)$ & 0.034 & NS & & \\
\hline $\mathrm{DCP} \geq 100(\mathrm{mAU} / \mathrm{ml})$ & $14(53.9 \%)$ & $20(16.7 \%)$ & $<0.0001$ & 4.19 & $1.63-11.0$ & 0.003 \\
\hline Tumor size $\geq 2(\mathrm{~cm})$ & $23(85.2 \%)$ & $71(58.2 \%)$ & 0.0054 & 3.37 & $1.10-12.8$ & 0.03 \\
\hline
\end{tabular}

MVI: Microvascular invasion; RR: relative risk; 95\%CI: 95\% confidence interval; HBs-Ag: hepatitis B surface antigen; HCV-Ab: anti-hepatitis C antibody; ICG-R15: indocyanine green retention rate at $15 \mathrm{~min}$; $99 \mathrm{~m}$ Tc-GSA: $99 \mathrm{~m}$ Tc-galactosyl human serum albumin; AFP, $\alpha$-fetoprotein; AFP-L3: Lens culinaris agglutinin-reactive fraction of AFP; DCP: des- $\gamma$-carboxy prothrombin; NS: not significant.

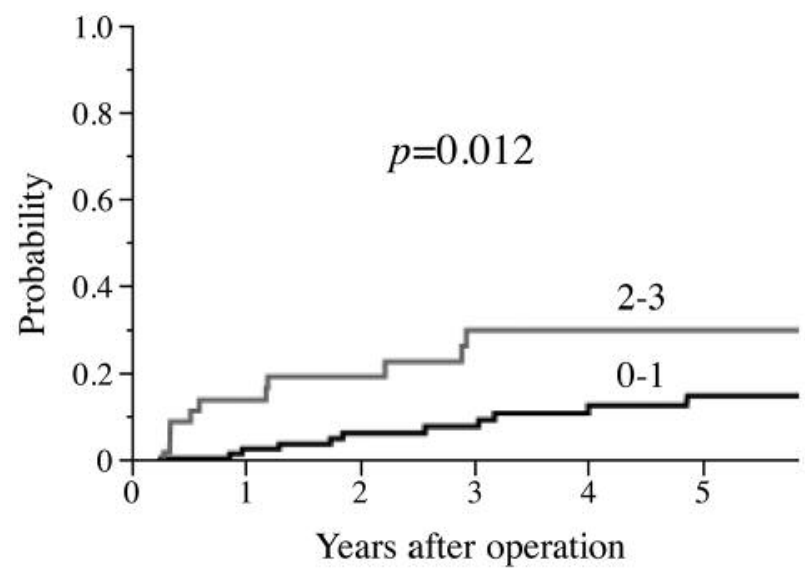

Figure 4. Local recurrence rate in patients who underwent radiofrequency ablation according to the number of risk factors for microvascular invasion (0-1 vs. 2-3).

hepatectomy or liver transplantation, the significance of MVI for patient outcome after RFA is uncertain. The only possible alternative is preoperative needle biopsy. However, we considered that needle biopsy prior to RFA is highly undesirable because it carries a risk of tumor dissemination or seeding (36). Therefore, in the present study, to address the significance of MVI for patient outcome, this predictive model was applied to the RFA cohort. As a result, in contrast to the hepatectomy cohort, the OS in patients with an MVI-
Table III. Predictive model estimating the probability of microvascular invasion.

\begin{tabular}{lcccc}
\hline Factors & $\begin{array}{c}\mathrm{AFP} \geq 15 \\
(\mathrm{ng} / \mathrm{ml})\end{array}$ & $\begin{array}{c}\mathrm{DCP} \geq 100 \\
(\mathrm{mAU} / \mathrm{ml})\end{array}$ & $\begin{array}{c}\text { Tumor size } \\
\geq 2(\mathrm{~cm})\end{array}$ & $\begin{array}{c}\text { Probability } \\
(\%)\end{array}$ \\
\hline 0 & - & - & - & 3.3 \\
1 & + & - & - & 9.4 \\
& - & + & - & 12.5 \\
2 & - & - & + & 10.3 \\
& + & + & - & 30.4 \\
& - & + & + & 32.6 \\
3 & + & - & + & 26.0 \\
\hline
\end{tabular}

AFP: $\alpha$-Fetoprotein; DCP: des- $\gamma$-carboxy prothrombin.

expected tumor (the number of risk factor 2-3) was significantly worse than those with an MVI-unexpected tumor (the number of risk factor 0-1) (Figure 3). Furthermore, in those patients, local recurrence at the ablated site was more frequent (Figure 4). These findings suggest that the presence of MVI is a poor-prognosis factor after RFA, and thus that RFA should be contraindicated for patients with an MVI-expected tumor.

Local recurrence after RFA remains a serious problem; its rates have been reported to range from 3.2-26\% (37-39). Local recurrence after RFA may be attributable to insufficient margin and/or the presence of vascular invasion of the tumor in the 
adjacent liver tissue. In the current study, the factors related to the presence of MVI in the resected specimens were elevated AFP and DCP, and larger tumor size (Table II), which were all reported to be risk factors for local recurrence after RFA (38-42). From the viewpoint of the risk of local recurrence, RFA may not be suitable for patients with the three factors identified in this study, namely those patients with MVI-expected HCC, even though their tumors are small.

The retrospective data analysis and small sample size from a single institution are the main limitations of the present study. In addition, survival analysis in the RFA cohort was based on the estimated MVI from a predictive model, and not on actual histological assessment. However, since tumor biopsy should be avoided because of the issues of tumor dissemination or seeding, it is difficult to investigate the role of MVI in long-term outcome following RFA. Finally, a validation study using an external cohort is required to confirm the results of the present study.

In conclusion, a predictive model of MVI was developed using three independent factors that were available preoperatively. MVI had limited prognostic value in solitary small-sized HCC when hepatectomy was performed. On the other hand, MVI expected by the proposed predictive model has significant roles in terms of survival and local recurrence following RFA for solitary small-sized HCC. When the HCC tumor is expected to be accompanied with MVI, RFA may not be suitable in terms of poorer survival and local disease control rates.

\section{References}

1 Bosch FX, Ribes J, Diaz M and Cleries R: Primary liver cancer: worldwide incidence and trends. Gastroenterology 127: S5-S16, 2014.

2 Jemal A, Bray F, Center MM, Ferlay J, Ward E and Forman D: Global cancer statistics. CA Cancer J Clin 61: 69-90, 2011.

3 Bruix J, Sherman $M$ and Practice Guidelines Committee AAftSoLD: Management of hepatocellular carcinoma. Hepatology 42: 1208-1236, 2005.

4 Lim KC, Chow PK, Allen JC, Chia GS, Lim M, Cheow PC, Chung AY, Ooi LL and Tan SB: Microvascular invasion is a better predictor of tumor recurrence and overall survival following surgical resection for hepatocellular carcinoma compared to the Milan criteria. Ann Surg 254: 108-113, 2011.

5 Chan SC, Fan ST, Chok KS, Cheung TT, Chan AC, Fung JY, Poon RT and Lo CM: Survival advantage of primary liver transplantation for hepatocellular carcinoma within the up-to-7 criteria with microvascular invasion. Hepatol Int 6: 646-656, 2012.

6 Unek T, Karademir S, Arslan NC, Egeli T, Atasoy G, Sagol O, Obuz F, Akarsu M and Astarcioglu I: Comparison of Milan and UCSF criteria for liver transplantation to treat hepatocellular carcinoma. World J Gastroenterol 17: 4206-4212, 2011.

7 Fan ST, Poon RT, Yeung C, Lam CM, Lo CM, Yuen WK, Ng KK, Liu CL and Chan SC: Outcome after partial hepatectomy for hepatocellular cancer within the Milan criteria. Br J Surg 98: 1292-1300, 2011.
8 Bertuzzo VR, Cescon M, Ravaioli M, Grazi GL, Ercolani G, Del Gaudio M, Cucchetti A, D'Errico-Grigioni A, Golfieri R and Pinna AD: Analysis of factors affecting recurrence of hepatocellular carcinoma after liver transplantation with a special focus on inflammation markers. Transplantation 91: 1279-1285, 2011.

9 Bhangui P, Vibert E, Majno P, Salloum C, Andreani P, Zocrato J, Ichai P, Saliba F, Adam R, Castaing D and Azoulay D: Intention-to-treat analysis of liver transplantation for hepatocellular carcinoma: living versus deceased donor transplantation. Hepatology 53: 1570-1579, 2011.

10 Sumie S, Kuromatsu R, Okuda K, Ando E, Takata A, Fukushima N, Watanabe Y, Kojiro M and Sata M: Microvascular invasion in patients with hepatocellular carcinoma and its predictable clinicopathological factors. Ann Surg Oncol 15: 1375-1382, 2008.

11 Lauwers GY, Terris B, Balis UJ, Batts KP, Regimbeau JM, Chang Y, Graeme-Cook F, Yamabe H, Ikai I, Cleary KR, Fujita S, Flejou JF, Zukerberg LR, Nagorney DM, Belghiti J, Yamaoka Y and Vauthey JN: Prognostic histologic indicators of curatively resected hepatocellular carcinomas: a multi-institutional analysis of 425 patients with definition of a histologic prognostic index. Am J Surg Pathol 26: 25-34,2002.

12 Sumie S, Nakashima O, Okuda K, Kuromatsu R, Kawaguchi A, Nakano M, Satani M, Yamada S, Okamura S, Hori M, Kakuma $\mathrm{T}$, Torimura $\mathrm{T}$ and Sata M: The significance of classifying microvascular invasion in patients with hepatocellular carcinoma. Ann Surg Oncol 21: 1002-1009, 2014.

13 Zhao H, Chen C, Fu X, Yan X, Jia W, Mao L, Jin H and Qiu Y: Prognostic value of a novel risk classification of microvascular invasion in patients with hepatocellular carcinoma after resection. Oncotarget 8: 5474-5486, 2017.

14 Schlichtemeier SM, Pang TC, Williams NE, Gill AJ, Smith RC, Samra JS, Lam VW, Hollands M, Richardson AJ, Pleass HC, Nozawa S, Albania M and Hugh TJ: A pre-operative clinical model to predict microvascular invasion and long-term outcome after resection of hepatocellular cancer: The Australian experience. Eur J Surg Oncol 42: 1576-1583, 2016.

15 Yang C, Wang H, Sheng R, Ji Y, Rao S and Zeng M: Microvascular invasion in hepatocellular carcinoma: is it predictable with a new, preoperative application of diffusionweighted imaging? Clin Imaging 41: 101-105, 2017.

16 Min JH, Kim YK, Lim S, Jeong WK, Choi D and Lee WJ: Prediction of microvascular invasion of hepatocellular carcinomas with gadoxetic acid-enhanced MR imaging: Impact of intra-tumoral fat detected on chemical-shift images. Eur J Radiol 84: 1036-1043, 2015.

17 Feng LH, Dong H, Lau WY, Yu H, Zhu YY, Zhao Y, Lin YX, Chen J, Wu MC and Cong WM: Novel microvascular invasionbased prognostic nomograms to predict survival outcomes in patients after R0 resection for hepatocellular carcinoma. J Cancer Res Clin Oncol 143: 293-303, 2017.

18 Lei Z, Li J, Wu D, Xia Y, Wang Q, Si A, Wang K, Wan X, Lau WY, Wu M and Shen F: Nomogram for preoperative estimation of microvascular invasion risk in hepatitis B virus-related hepatocellular carcinoma within the Milan criteria. JAMA Surg 151: 356-363, 2016.

19 Pote N, Cauchy F, Albuquerque M, Voitot H, Belghiti J, Castera L, Puy H, Bedossa P and Paradis V: Performance of PIVKA-II for early hepatocellular carcinoma diagnosis and prediction of microvascular invasion. J Hepatol 62: 848-854, 2015. 
20 Shirabe K, Toshima T, Kimura K, Yamashita Y, Ikeda T, Ikegami T, Yoshizumi T, Abe K, Aishima S and Maehara Y: New scoring system for prediction of microvascular invasion in patients with hepatocellular carcinoma. Liver Int 34: 937-941, 2014.

21 Roayaie S, Blume IN, Thung SN, Guido M, Fiel MI, Hiotis S, Labow DM, Llovet JM and Schwartz ME: A system of classifying microvascular invasion to predict outcome after resection in patients with hepatocellular carcinoma. Gastroenterology 137: 850-855, 2009.

22 Hirokawa F, Hayashi M, Miyamoto Y, Asakuma M, Shimizu T, Komeda $\mathrm{K}$, Inoue $\mathrm{Y}$ and Uchiyama $\mathrm{K}$ : Outcomes and predictors of microvascular invasion of solitary hepatocellular carcinoma. Hepatol Res 44: 846-853, 2014.

23 Xu P, Zeng M, Liu K, Shan Y, Xu C and Lin J: Microvascular invasion in small hepatocellular carcinoma: is it predictable with preoperative diffusion-weighted imaging? J Gastroenterol Hepatol 29: 330-336, 2014.

24 Yamashita Y, Tsuijita E, Takeishi K, Fujiwara M, Kira S, Mori M, Aishima S, Taketomi A, Shirabe K, Ishida T and Maehara Y: Predictors for microinvasion of small hepatocellular carcinoma $</=2 \mathrm{~cm}$. Ann Surg Oncol 19: 2027-2034, 2012.

25 Imai K, Beppu T, Chikamoto A, Doi K, Okabe H, Hayashi H, Nitta $\mathrm{H}$, Ishiko T, Takamori $\mathrm{H}$ and Baba $\mathrm{H}$ : Comparison between hepatic resection and radiofrequency ablation as first-line treatment for solitary small-sized hepatocellular carcinoma of 3 cm or less. Hepatol Res 43: 853-864, 2013.

26 Imai K, Beppu T, Chikamoto A, Mima K, Okabe H, Hayashi H, Nitta H, Ishiko $\mathrm{T}$ and Baba H: Salvage treatment for local recurrence of hepatocellular carcinoma after local ablation therapy. Hepatol Res 44: E335-345, 2014

27 Imai K, Beppu T, Yamao T, Okabe H, Hayashi H, Nitta H, Hashimoto D, Mima K, Nakagawa S, Sakamoto K, Chikamoto A, Ishiko $\mathrm{T}$ and Baba $\mathrm{H}$ : Clinicopathological and prognostic significance of preoperative serum zinc status in patients with hepatocellular carcinoma after initial hepatectomy. Ann Surg Oncol 21: 3817-3826, 2014.

28 Dindo D, Demartines N and Clavien PA: Classification of surgical complications: a new proposal with evaluation in a cohort of 6336 patients and results of a survey. Ann Surg 240: 205-213, 2004.

29 Hori T, Nagata K, Hasuike S, Onaga M, Motoda M, Moriuchi A, Iwakiri H, Uto H, Kato J, Ido A, Hayashi K and Tsubouchi $\mathrm{H}$ : Risk factors for the local recurrence of hepatocellular carcinoma after a single session of percutaneous radiofrequency ablation. J Gastroenterol 38: 977-981, 2003.

30 Imai K, Benitez CC, Allard MA, Vibert E, Cunha AS, Cherqui D, Castaing D, Bismuth H, Baba $\mathrm{H}$ and Adam R: Failure to Achieve a 2-Stage Hepatectomy for Colorectal Liver Metastases: How to Prevent It? Ann Surg 262: 772-778, 2015.

31 Imai K, Castro Benitez C, Allard MA, Vibert E, Sa Cunha A, Cherqui D, Castaing D, Bismuth H, Baba H and Adam R: Potential of a cure in patients with colorectal liver metastases and concomitant extrahepatic disease. J Surg Oncol 115: 488-496, 2017.

32 Iguchi T, Shirabe K, Aishima S, Wang H, Fujita N, Ninomiya M, Yamashita Y, Ikegami T, Uchiyama H, Yoshizumi T, Oda Y and Maehara Y: New Pathologic Stratification of Microvascular Invasion in Hepatocellular Carcinoma: Predicting Prognosis After Living-donor Liver Transplantation. Transplantation 99: 1236-1242, 2015.
33 Portolani N, Baiocchi GL, Molfino S, Benetti A, Gheza F and Giulini SM: Microvascular infiltration has limited clinical value for treatment and prognosis in hepatocellular carcinoma. World J Surg 38: 1769-1776, 2014.

34 Shindoh J, Andreou A, Aloia TA, Zimmitti G, Lauwers GY, Laurent A, Nagorney DM, Belghiti J, Cherqui D, Poon RT, Kokudo N and Vauthey JN: Microvascular invasion does not predict long-term survival in hepatocellular carcinoma up to 2 $\mathrm{cm}$ : reappraisal of the staging system for solitary tumors. Ann Surg Oncol 20: 1223-1229, 2013.

35 Huang C, Zhu XD, Ji Y, Ding GY, Shi GM, Shen YH, Zhou J, Fan J and Sun HC: Microvascular invasion has limited clinical values in hepatocellular carcinoma patients at Barcelona Clinic Liver Cancer (BCLC) stages 0 or B. BMC Cancer 17: 58, 2017.

36 Silva MA, Hegab B, Hyde C, Guo B, Buckels JA and Mirza DF: Needle track seeding following biopsy of liver lesions in the diagnosis of hepatocellular cancer: a systematic review and meta-analysis. Gut 57: 1592-1596, 2008.

37 Hong SN, Lee SY, Choi MS, Lee JH, Koh KC, Paik SW, Yoo BC, Rhee JC, Choi D, Lim HK, Lee KW and Joh JW: Comparing the outcomes of radiofrequency ablation and surgery in patients with a single small hepatocellular carcinoma and well-preserved hepatic function. J Clin Gastroenterol 39: 247-252, 2005.

38 Lam VW, Ng KK, Chok KS, Cheung TT, Yuen J, Tung H, Tso WK, Fan ST and Poon RT: Risk factors and prognostic factors of local recurrence after radiofrequency ablation of hepatocellular carcinoma. J Am Coll Surg 207: 20-29, 2008.

39 Shiina S, Tateishi R, Arano T, Uchino K, Enooku K, Nakagawa H, Asaoka Y, Sato T, Masuzaki R, Kondo Y, Goto T, Yoshida H, Omata $M$ and Koike K: Radiofrequency ablation for hepatocellular carcinoma: 10-year outcome and prognostic factors. Am J Gastroenterol 107: 569-577, 2012.

40 Mulier S, Ni Y, Jamart J, Ruers T, Marchal G and Michel L: Local recurrence after hepatic radiofrequency coagulation: multivariate meta-analysis and review of contributing factors. Ann Surg 242: 158-171, 2005.

41 Nitta H, Nakagawa S, Kaida T, Arima K, Higashi T, Taki K, Okabe H, Hayashi H, Hashimoto D, Chikamoto A, Ishiko T, Beppu T and Baba H: Pre-treatment double- or triple-positive tumor markers are predictive of a poor outcome for patients undergoing radiofrequency ablation for hepatocellular carcinoma. Surg Today 47: 375-384, 2017.

42 Nouso K, Matsumoto E, Kobayashi Y, Nakamura S, Tanaka H, Osawa T, Ikeda H, Araki Y, Sakaguchi K and Shiratori Y: Risk factors for local and distant recurrence of hepatocellular carcinomas after local ablation therapies. J Gastroenterol Hepatol 23: 453-458, 2008. 